Corrigendum

\title{
Corrigendum to "Valorization of Oued Sebou Natural Sediments (Fez-Morocco Area) as Adsorbent of Methylene Blue Dye: Kinetic and Thermodynamic Study"
}

\author{
Abdelaziz Dra, ${ }^{1}$ Karim Tanji $\left(\mathbb{D},{ }^{1}\right.$ Abdellah Arrahli $\left(\mathbb{D},{ }^{2}\right.$ El Mustafa Iboustaten, ${ }^{1}$ \\ Abdelali El Gaidoumi $\mathbb{D}^{1,},{ }^{1,3}$ Achaimae Kherchafi, ${ }^{1}$ Aziz Chaouni Benabdallah, \\ and Abdelhak Kherbeche ${ }^{1}$ \\ ${ }^{1}$ Laboratory of Catalysis, Materials and Environment, Higher School of Technology, \\ Sidi Mohamed Ben Abdellah University of Fez, Fez 30000, Morocco \\ ${ }^{2}$ Euromed Research Center, National Institute of Applied Sciences, Euro-Mediterranean University of Fez, Fez, Morocco \\ ${ }^{3}$ Higher School of Technology of Khenifra, Sultan Moulay Slimane University, Beni Mellal, Morocco
}

Correspondence should be addressed to Karim Tanji; karimtanji1992@gmail.com

Received 19 August 2020; Accepted 20 August 2020; Published 30 September 2020

Copyright $(92020$ Abdelaziz Dra et al. This is an open access article distributed under the Creative Commons Attribution License, which permits unrestricted use, distribution, and reproduction in any medium, provided the original work is properly cited.

In the article titled "Valorization of Oued Sebou Natural Sediments (Fez-Morocco Area) as Adsorbent of Methylene Blue Dye: Kinetic and Thermodynamic Study" [1], the author Abdellah Arrahli was affiliated to "Laboratory of Catalysis, Materials and Environment, Higher School of Technology, Sidi Mohamed Ben Abdellah University of Fez, 30000 Fez, Morocco," which is incorrect. The correct affiliation for this author is as follows:

Euromed Research Center, National Institute of Applied Sciences, Euro-Mediterranean University of Fez, Morocco.

E-mail address: a.arrahli@insa.ueuromed.org.

The corrected list of affiliations is shown in the author information above.

\section{References}

[1] A. Dra, K. Tanji, A. Arrahli et al., "Valorization of oued sebou natural sediments (Fez-Morocco Area) as adsorbent of methylene blue dye: kinetic and thermodynamic study," The Scientific World Journal, vol. 2020, Article ID 2187129, 8 pages, 2020. 